\title{
DYSFUNCTIONAL UTERINE BLEEDING AND ITS MANAGEMENT STRATEGY
}

\section{ABSTRACT}

Dysfunctional uterine bleeding (DUB) is a diagnosis of exclusion. An adequate examination of the abdomen and the pelvis and uterine curettage, hysteroscopy or at least an endometrial biopsy is essential to exclude organic disease of the uterus. It occurs most frequently at the extremes of menstrual life, but it can develop at any intervening time.

The objectives of treatment are to control the acute bleeding, avert future episodes, and prevent a serious long-term consequence of anovulation, endometrial cancer. The mainstay of treatment has been medical therapy although surgical intervention is required in some cases. If the bleeding is severe and / or recurrent or the medical treatment fails, re-evaluation is needed.

Adolescent DUB is due to immaturity of the hypothalamus and pituitary and menstrual cycles may be anovulatory. In teenage girls organic disease is rare and DUB usually gets resolved spontaneously. That's why they are treated expectantly and curettage is often delayed.

In the middle years of reproductive life (20-39yrs), benign organic disease is common, and curettage is usually performed to exclude complications of pregnancy and other disease. Conservative therapy is usually indicated, though hysterectomy may be indicated if bleeding is severe or recurrent and patient has completed her family.

Perimenopausal DUB is due to the decreased number of ovarian follicles and their increased resistance to gonadotrophin stimulation, there is a possibility of malignancy. So, these women should always be investigated by curettage or hysteroscopy without delay. Although conservative therapy may be tried as a temporizing measure, hysterectomy is often indicated.

Key Words: Dysfunctional uterine bleeding, curettage, hysteroscopy, and progestogen.

Address for correspondence : $\quad$ Dr. Ganesh Dangal, MBBS, MD, Chief, Gynaecological Oncology

B. P. Koirala Memorial Cancer Hospital, Chitwan, Nepal.

Ph. No.: 00977-56-24501, Ext. 9140, Fax: 00977-56-23747

Email: gareshma@hotmail.com 


\section{INTRODUCTION}

Disturbances in the pattern of menstruation are a common clinical presentation. Dysfunctional uterine bleeding is defined as abnormal and excessive endometrial bleeding without structural pathology. ${ }^{1}$ It has also been defined as heavy and / or irregular menstruation in the absence of recognizable pelvic pathology, pregnancy or general bleeding disorders. ${ }^{2}$ It commonly occurs at the extremes of reproductive life, when anovulatory DUB is common. During these periods, it is secondary to an estrogen withdrawal. It can have its origin in an endocrine imbalance or can occur in normal menstrual cycles (ovulatory DUB).

The social and economic cost of DUB is considerable. About one third of the hysterectomies are carried out for menstrual disturbances alone. ${ }^{3}$
In this article, the clinical management of DUB is re-viewed. The current approach to the treatment of DUB will be discussed.

Since the diagnosis of DUB rests on excluding the pathologic causes, it is important to know the differential diagnosis of DUB. Upto $40 \%$ of women with DUB will eventually end up with some other diagnosis if intensively investigated. ${ }^{4}$ Psychiatric morbidity is also associated with DUB. Community studies have shown that women who score highly on psychiatric scores are more likely to complain of menstrual disturbances. ${ }^{5,6}$

DUB includes any condition of abnormal uterine bleeding in the absence of pregnancy, neoplasm, infection or other intra uterine lesions. Such bleeding is most often the result of endocrinologic dysfunction that inhibits normal ovulation.

\section{Table 1: Differential Diagnosis of Dysfunctional Uterine Bleeding}

\begin{tabular}{|l|l|}
\hline Hormonal factors & Local Pathology (Vagina,Cervix, Uterus) \\
Anovulation & Sexually transmitted disease \\
Polycystic ovary Syndrome & Foregin body (e.g., tampon, intrauterine device) \\
Thyroid dysfunction & Polyp (cervix,uterus) \\
Depot medroxyprogesterone acetate & Trauma \\
Oral contraceptive & Dysplasia or malignancy \\
Levonorgestrel implants & \\
& Bleeding Diathesis \\
Pregnancy complications & Thrombocytopenia \\
Threatened or spontaneous abortion & Platelet dysfunction \\
Ectopic pregnancy & Inherited clotting factor deficiencies \\
Incomplete elective abortion & Vitamin K deficiency \\
Postabortion endometritis & Anticoagulant therapy \\
& Consumption coagulopathy \\
\hline
\end{tabular}

BASIC KNOWLEDGE OF NORMAL MENSTRUAL CYCLE

Normal menstruation results from progesterone withdrawal from estrogen-primed endometrium.
Menstrual cycle resulting in ovulation is the result of a complex interaction between the various organs as shown in Fig.1. Dysfunction at any level can interfere with ovulation and the menstrual cycle. 


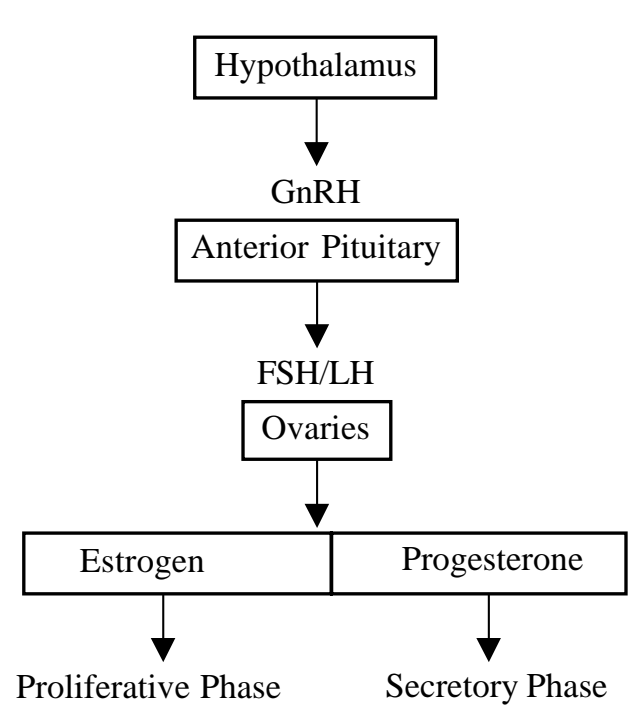

Fig. 1: Pathway of action of hormones for normal menstrual function

\section{PATHOLOGY OF DUB}

The pathology in DUB is varied. The important feature of one group of DUB is the derangement of the hypothalamo-pituitary-ovarian axis resulting in anovulatory cycles. The lack of progesterone gives rise to unopposed estrogenic stimulation of the endometrium. The excessively thickened endometrium, without progestogenic influence, is unstable and irregular sloughing occurs. In general, the more prolonged the anovulation; greater is the risk of excessive bleeding. ${ }^{7}$ This is the form of DUB seen most often in adolescent girls.

Defective corpus luteum following ovulation can cause ovulatory DUB. This results in inadequate stabilization of the endometrium, which sloughs irregularly. Irregular shedding occurs when there is a persistent corpus luteum whereby the progestogenic support is not withdrawn after 14 days, as normally, but continues beyond that period. This is ovulatory DUB. ${ }^{7}$

\section{CHRONIC ANOVULATION}

Chronic anovulation is the most frequent cause of DUB. ${ }^{8}$ The state of chronic anovulation is the result of unopposed estrogen stimulation of the endometrium with consequent irregular breakdown and bleeding. Anovulation is frequent in the perimenarchal girl. Prolonged estrogen stimulation can result in endometrium that outgrows its blood supply and has asynchronous development of endometrial glands, stroma and blood vessels. Any failure of progesterone production can also profoundly affect endometrial glands, stroma and blood vessel. It has multiple endocrine etiologies like thyroid disorders, hyperprolactinemia, and hormone-producing ovarian tumors, Cushing's disease and most importantly polycystic ovary or Stein-Leventhal syndrome.

\section{ABNORMAL OVULATION}

Abnormal ovulation (ovulatory DUB) occurs in 15$20 \%$ of DUB patients and they have secretory endometrium, indicative of at least intermittent, if not regular, ovulation. ${ }^{8}$ Ovulatory patients with abnormal bleeding are more likely to have an underlying organic pathology and are not, therefore, true DUB patients by strict definition. In general, ovulatory DUB is difficult to treat medically. The characteristics of DUB are variable, from infrequent heavy flow to almost continuous spotting or bleeding.

\section{MANAGEMENT}

The gynecologist must follow a stepwise evaluation to rule out all causes of the abnormal bleeding. The first step is to determine that the frequency and / or the amount of blood loss is excessive, then further evaluation is required. The next step is to determine whether the bleeding is ovulatory or anovulatory in nature. 


\section{DIAGNOSIS}

A full history and clinical examination should be performed for the patient work-up. If these suggest systemic disease further investigation may be warranted. Abnormalities on pelvic examination should be investigated by ultrasound, with laparoscopy if required.

Cyclical (regular) bleeding preceded by premenstrual symptoms (mastalgia, water weight gain, mood swings, or abdominal cramps) is likely to be ovulatory. Whereas prolonged bleeding occurring at irregular intervals following months of amenorrhoea is most likely anovulatory.

A raised (by $0.3-0.6^{\circ} \mathrm{C}$ ) basal body temperature, serum progesterone level (> $3 \mathrm{ng} / \mathrm{ml})$ and /or secretory changes in the endometrium seen at biopsy performed at the onset of the bleeding all are evidence of ovulation. ${ }^{9}$

The diagnosis of DUB by exclusion of organic disease of the genital tract may occasionally cause difficulty as it depends upon what is regarded as organic disease and upon the extent of the investigation performed to exclude disease of the genital tract.

Patients under 40 years old have a very low risk of developing endometrial carcinoma ${ }^{10}$ and so pathological examination of the endometrium is not mandatory. ${ }^{11}$ Medical treatment can be used as first line treatment with invasive investigation only if symptoms persist. The risk of endometrial carcinoma in patients with perimenopausal DUB, however, is around $1 \%$ and so endometrial sampling is important. ${ }^{10}$

\section{INVESTIGATIONS}

1. Blood tests: Haemoglobin, thyroid function tests and levels of HCG, FSH, LH, prolactin and serum androgens if indicated or screening for bleeding diathesis if there are suggestive features.

2. Endometrial pathology detection by

a) D and C \& b) hysteroscopy

Older women with menstrual disturbances, young women with irregular bleeding or young women (<40 yr.) who fail to respond to treatment should undergo some form of endometrial assessment. Organic diseases of the genital tract may be missed even by curettage. It is thus important to perform a repeat curettage and other appropriate investigation in all cases of recurrent or severe abnormal uterine bleeding. For women in whom investigation is appropriate, hysteroscopy appears to be more sensitive than dilatation and curettage in the diagnosis of endometrial abnormality.

3. Laparoscopy: It may be helpful in those women who have unsuccessful therapeutic trial.

\section{TREATMENT}

Women require rapid, safe and effective treatment for their menstrual problems.

Table II: Management strategy in DUB ${ }^{12}$

\begin{tabular}{|l|l|l|l|}
\hline \multicolumn{1}{|c|}{ Age (years) } & \multicolumn{1}{|c|}{ D and C or hysteroscopy } & $\begin{array}{l}\text { Conservative (hormone, anti- } \\
\text { PG, or anti-fibrinolytic) }\end{array}$ & \multicolumn{1}{|c|}{ Hysterectomy } \\
\hline Under 20 & $\begin{array}{l}\text { Rarely, only if bleeding is } \\
\text { severe or non responsive }\end{array}$ & $\begin{array}{l}\text { Always, if bleeding is recurrent } \\
\text { or severe }\end{array}$ & Never \\
\hline $\begin{array}{l}\text { 20-39 (family } \\
\text { not complete) }\end{array}$ & $\begin{array}{l}\text { Always, but may defer if } \\
\text { bleeding is regular and biopsy } \\
\text { and examination are normal }\end{array}$ & $\begin{array}{l}\text { First resort after D \& C or } \\
\text { hysteroscopy }\end{array}$ & $\begin{array}{l}\text { Seldom, only if } \\
\text { conservative } \\
\text { treatment fails }\end{array}$ \\
\hline $\begin{array}{l}40 \text { and over } \\
\text { family complete) }\end{array}$ & $\begin{array}{l}\text { Mandatory in all cases } \\
\text { without delay }\end{array}$ & $\begin{array}{l}\text { Temporizing and if ysterectomy } \\
\text { refused, imminent menopause }\end{array}$ & $\begin{array}{l}\text { First resort if } \\
\text { bleeding is recurrent }\end{array}$ \\
\hline
\end{tabular}




\section{GENERAL MEASURES}

1. A menstrual calendar for 3 months.

2. Iron therapy often and sometimes blood transfusion also.

3. Treatment of secondary disease if present.

\section{SPECIFIC MEASURES}

\section{a) Surgical treatment}

Curettage is essentially an investigative procedure; the MBL is reduced only in the first but not subsequent periods following it. ${ }^{13}$

1. Endometrial ablation techniques

Ablation or destruction of the endometrium has been advocated for treatment of chronic abnormal bleeding unresponsive to medical management. It has good results and is becoming widely used but most of these are not available in Nepal.
a. Laser ablation
b. Endometrial resection
c. Other methods-Rollerball coagulation, Microwave and ultrasound methods, etc.

2. Hysterectomy
Hysterectomy offers complete cure in recurrent DUB. It should be the last resort in younger women.

a. If atypical hyperplasia (in D\&C) persists, very high dose of progestin protocols (MPA, 30mg, daily for 3 month) can be tried but hysterectomy must be considered.

b. Unresponsive recurrent DUB, usually in over 40 's \& family complete, is treated by hysterectomy.

\section{b) Medical treatment}

Drug treatments are very effective in some women, although the response tends to be variable.

Drugs commonly used in treatment of DUB are:

1. Progestogens, e.g., Norethisterone

2. Combined OC pills

3. NSAID's, e.g., Mefenamic acid

4. Estrogens

5. Antigonadotrophins, e.g., danazol

6. Antifibrinolytics, e.g., tranexamic acid

7. GnRH analogues

8. Ethamsylate

9. Anti-anemics

Table III: Management of Dysfunctional Uterine Bleeding in the Adolescent ${ }^{12}$ Mild (Haemodynamically Stable Light to Moderate flow, Haemoglobin > 12g/dL)

Reassurance

Menstrual calendar

Multivitamin with iron

Reevaluation in 3 months

Hormonal therapy optional

Moderate (Haemodynamically Stable, Moderate to Heavy flow, Haemoglobin 10-12 g/dL)

Progestin or oral contraceptive $1 / 35 \mathrm{mg}$

One pill every 6-12 $\mathrm{h}$ for $24-48 \mathrm{~h}$ until bleeding stops

Taper to one pill daily by day 5 , then

Begin new 28 day packet

Continue for 3-6 months

Iron supplementation

Menstrual calendar

Reevaluation in 1-3 months

Severe (Haemodynamically Stable, Heavy Flow, Haemoglobin $<10$ g/dL)

As above if reliable and able to tolerate hormonal therapy.

Otherwise, hospitalize until bleeding stops on above regimen

Life Threatening (Haemodynamically Unstable, Heavy flow, Hemoglobin $<10$ g/dL)

Hospitalise

Intravenous fluid and/or transfusion

Oral contraceptive $1 / 50 \mathrm{mg}$ every $6 \mathrm{~h}$

If bleeding does not decrease within 2 doses, add intravenous conjugated estrogen, 25 mg every 6-hour. 
Table IV: Management of DUB based on endometrial histology in the second half of cycle ${ }^{12}$

\begin{tabular}{|l|l|}
\hline Endometrial Histology & Treatment \\
\hline Absent/deficient endometrium & Emergency: Premarin 25mg i.v. \\
& $\begin{array}{l}\text { Acute: Unopposed estrogen 21 days then OC } \\
\text { Chronic: Oestrogen dominant OC }\end{array}$ \\
\hline Proliferative/ hyperplastic endometrium & $\begin{array}{l}\text { Acute: Higher dose progestogen } \\
\text { Chronic: Progestogens (days 15-25) or(days 5-20) }\end{array}$ \\
\hline Normal (Secretary) & $\begin{array}{l}\text { Acute: Antifibrinolytics } \\
\text { Chronic: Low dose OC and/or NSAID's }\end{array}$ \\
\hline
\end{tabular}

I.V., intra-venously; OC, oral contraceptive; PG, prostaglandin

\section{1) PROGESTOGENS}

They have been available for at least 25 years. The first of the present day medical treatments was progesterone, initially described by Albright in 1938. Monthly administration of a progestational agent is used to regularize the endometrial shedding and to protect against the development of endometrial cancer. Most women with normal menstrual cycles will have occasional anovulatory cycle resulting in DUB. They can be treated with a single course of progestogen, i.e., $10 \mathrm{mg}$ of medroxyprogesterone acetate for 5 to 10 days.

Endometrial histology in the second half of the cycle is helpful for the appropriate and effective hormonal treatment. Because most patients with DUB have an underlying etiology of chronic anovulation with unopposed estrogen stimulation of the endometrium, medical treatment with progestational compounds is the mainstay of therapy. Adequate progestin stimulation will decrease DNA synthesis and cell proliferation, deplete estrogen receptors, and increase the conversion of estradiol to the less potent estrone sulfate. These effects will induce maturation of the endometrium, healing of superficial breaks, enhancement of the stromal matrix with increased structural stability, and cessation of bleeding. ${ }^{8}$

Failure to have withdrawal bleeding could signify pregnancy, development of a hypoestrogenic state or, rarely induction of ovulation by progestin stimulation of the estrogen-primed patient. Whitehead recommends 12 days of progestin every month to counteract the estrogen's proliferative effect. ${ }^{13}$ Medroxyprogesterone acetate, $10 \mathrm{mg}$, or Norethindrone, $5 \mathrm{mg}$ per day, may be prescribed. It is convenient to start each new course on the first day of each month; regular withdrawal can be expected to start either during the last 2 days of progesterone or within several days of the last dose.

Table V: Progestational treatment of DUB ${ }^{9}$

\begin{tabular}{|l|l|l|}
\hline \multicolumn{1}{|c|}{ Treatment } & \multicolumn{1}{|c|}{ Acute } & \multicolumn{1}{c|}{ Chronic } \\
\hline Intramuscular route & & \\
Progesterone in oil & $100-200 \mathrm{mg}$ & \\
Depot medroxyprogesterone acetate & $150 \mathrm{mg}$ & $150 \mathrm{mg}$ every $3 \mathrm{month}$ \\
Oral Preparations & & \\
Medroxyprogesterone acetate (MPA) & $20-40 \mathrm{mg} / \mathrm{d}$ & $10 \mathrm{mg} / \mathrm{d} \times 12 \mathrm{~d}$ \\
Norethindrone (NED) & $1-5 \mathrm{mg} / \mathrm{d}$ & $1 \mathrm{mg} / \mathrm{d} \mathrm{x} \times 12 \mathrm{~d}$ \\
Oral contraceptives (OC) & $1-4 \mathrm{tabs} / \mathrm{d}$ & $1 \mathrm{tab} / \mathrm{d}$
\end{tabular}


a) Oral route: Progestogen therapy is administered cyclically either in the second half (luteal phase treatment from the $15^{\text {th }}$ to the $25^{\text {th }}$ day) or throughout the menstrual cycle (whole cycle treatment-from the 5 th to the $25^{\text {th }}$ day).

b) Depot preparation of Norethisterone and medroxyprogesterone acetate: If used for long enough they induce amenorrhoea, but unfortunately during the early months bleeding tends to be unpredictable and can be heavy. This is the reason for discontinuing treatment and systemic side effects are a problem.

c) IUD- releasing levonorgestrel (for 5 years) induces endometrial atrophy. As with all progestogen only pills, break through bleeding is a problem. Local delivery of progestational agents by way of an IUD has been demonstrated by Milsom and colleagues to be extremely effective. ${ }^{14}$ They have the potential to provide long-term therapy for patients with chronic bleeding unresponsive to other therapies.

\section{2) COMBINED ESTROGEN / PROGESTERONE FORMULATIONS}

Cyclical therapy is the most widely used and effective therapy. Medical treatment for those with heavy bleeding or with bleeding that follows several months of amenorrhoea. The best way is to give oral contraceptives; it can be stopped after 3 to 6 months and observation to see if there is establishment of a normal menstrual pattern. Many of them develop chronic anovulation and ongoing treatment may be indicated.

Chronic unopposed estrogen can produce a very lush endometrium that can bleed heavily during progestin withdrawal. Speroff recommends treatment using combination oral contraceptives in a step-down regimen. ${ }^{15}$ Two to four pills are given daily on every 6 to 12 hours, for 5 to 7 days for acute control of bleeding. This will usually control acute bleeding within 24 to 48 hours; withdrawal of medication will result in a heavy bleed. On the fifth day of this bleed a low dose cyclic oral contraceptive is started and repeated for three cycles to allow orderly regression of the excessive proliferative endometrium.

Alternatively, the dosage of combination pills can be tapered (four times a day, then three times a day, then two times a day) over 3 to 6 days and then continued at one everyday. Combination oral contraceptives induce atrophy of the endometrium, because the chronic estrogen progestin exposure suppresses pituitary gonadotrophins and inhibits endogenous steroidogenesis. They are useful for long term management of DUB in patients without contraindications and have the added benefit of pregnancy prevention.

Particularly in perimenarchal patients, heavy prolonged bleeding can denude the basal endometrium and make it unresponsive to progestin. Curettage for control of hemorrhage is contraindicated because of a high risk of development of intra uterine synechiae (Asherman's syndrome) if the basalis is curetted. OC is safe in women upto and over the age of 40 who are not obese, do not smoke and are not hypertensive.

\section{3) NSAID'S (ANTI - PROSTAGLANDINS), e.g., MEFENAMIC ACID}

Menorrhagia can be reduced by non-steroidal antiinflammatory medications. Fraser \& Shearman demonstrated NSAID'S to be most effective when given for 7 to 10 days before the expected onset of menstruation in ovulatory DUB patients ${ }^{16}$, but they are commonly started with the onset of menses and continued throughout the bleeding episode with good success. They reduce menstrual blood loss (MBL) and may be of greatest benefit in ovulatory 
DUB where the amount of prostanoid release is higher.

\section{4) ESTROGEN ALONE}

Oestrogen therapy is rarely used in the treatment of DUB. It may be of value in arresting haemorrhage particularly in case of atrophic or inadequate endometrium. It may also be indicated in cases of DUB secondary to depot progestogen (Depot provera).

High dose intravenous estrogen (conjugated estrogens $25 \mathrm{mg}$ every 4 hours until bleeding abates) will give acute control by proliferative repair of the endometrium and by direct effect on coagulation, including increased fibrinogen and platelet aggregation. A progestin alone or oral conjugated estrogen in combination with a progestin can then be used to induce orderly withdrawal bleeding.

\section{5) ANTIGONADOTROPHINS, e.g., DANAZOL}

It causes endometrial atrophy and reduces pituitary gonadotrophin secretion. It must be given continuously (cyclical administration is ineffective). About $200 \mathrm{mg}$ daily continuously for 3 months is given. It is probably best reserved as a third line agent when other forms of therapy may be contraindicated.

\section{6) ANTIFIBRINOLYTICS, e.g., TRANEXAMIC ACID}

They are given at the time of menstruation and are effective in most types of DUB. They are probably best regarded as second line agents, either alone or in combination.

\section{7) GNRH AGONIST}

It results in amenorrhoea. Long-acting derivative of GnRH agonist down- regulates pituitary synthesis of FSH and LH and induces "medical castration". Withdrawal of endogenous steroid stimulation will result in endometrial atrophy. At least 2 to 4 weeks are required for adequate suppression of gonadotrophin production and inhibition of steroidogenesis.

\section{8) ETHAMSYLATE}

It is used infrequently.

\section{9) ANTI-ANEMIC}

Iron is prescribed for anemic patients.

\section{CONCLUSION}

Dysfunctional uterine bleeding remains one of the commonest reasons for women to seek medical attention. Detailed work-up of the patients is needed to establish the diagnosis by excluding organic problems. At present, the diagnosis of DUB is inadequate. Various treatment modalities for DUB are available. The mainstay of treatment, i. e., medical therapy may result in symptomatic relief but the long-term outcome is not encouraging. Therefore gynaecologists should always counsel the patients about all aspects of DUB management.

\section{ACKNOLEDGEMENT}

I would like to acknowledge the interest shown by my doctor colleagues to this subject matter. I would like to thank Dr. Hari Pd. Dhakal for his suggestions and comments and my wife Reshma is highly appreciated for the word processing of this article. 


\section{REFERENCES}

1. Polaneczky MM, Slap GB. Menstrual disorders in the adolescent: Dysmenorrhoea and dysfunctional uterine bleeding. Pediaatr Rev 1992; 13: 83-87.

2. Lumsden M, Normal J. Menstruation and menstrual abnormality. In: Shaw RW, Soutter WP, Stanton SL (eds) Gynaecology, $2^{\text {nd }}$ edn. London, Churchill Livingstone, 1997: 421-439.

3. Coulter A, Mc Pherson K, Vessey M. Do British Women undergo too many or too few hysterectomies? Soc Sci Med 1988; 27:987-94.

4 Beazley JM. Dysfunctional uterine haemorrhage. Br J Hosp Med 1972; 7:573.

5. Ballinger CB. Psychiatric morbidity and menopause: screening of a general population sample. Br Med J 1975; iii: 344-46.

6. Gath D, Osborn M, Bungay G et al. Psychiatric disorder and gynaecological symptoms in middleaged women: a community survey. Br Med J1987; 294 :213-218.

7. Spence JE. Anovulation and monophasic cycles. Ann N Y Acad Sci 1997; 16: 173-176.

8. Butler WJ. Normal and abnormal uterine bleeding. In: Rock JA, Thompson JD (eds) . Te Linde's Operative Gynaecology, $8^{\text {th }} \mathrm{ed}^{\text {n }}$. Philadelphia, Lipincott-Raven 1997: 453-475.

9. Bayer SR, DeCherney AH. Clinical manifestations and treatment of dysfunctional uterine bleeding. JAMA-India 1993; 13 (3) : 299-306.
10. Mackenzie JZ, Bibby JG. Critical assessment of dilatation and curettage in 1029 women. Lancet 1978; ii: 566-69.

11. Grimes DA. Diagnostic dilatation and curettage: a reappraisal Am J Obstet Gynecol1982;142:16

12. Sharma JB. Management strategies in Dysfunctional uterine bleeding. Obstetrics and Gynaecology Today 2000; 5 (11) : 39-46.

13. Whitehead MI, Frazier D. The effects of oestrogens and progestogens on the endometrium. Obstet Gynaecol Clin North Am 1987; 14: 299.

14. Milsom I, Anderson K, Andersch B, et al. A comparison of flunbiprofen, tranexamic acid and a levonorgestrel releasing intrauterine contraceptive device in the treatment of idiopathic menorrhagia. Am J Obstet Gynecol $1991 ; 164: 879$.

15. Speroff L, Glass RH, Kase NG. Dysfunctional uterine bleeding. In: Clinical gynaecologic endocrinology and infertility, ed 5. Baltimore, Williams and Wilkins, 1994.

16. Fraser IS, Pearse C, Shearman RP, et al. Efficacy of mefenamic acid in patients with a complaint of menorrhagia. Obstet Gynecol 1981; 58: 543. 